\title{
Review of Literature on Graduate Employability
}

\author{
Erabaddage Gishan Tharanga Sumanasiri ${ }^{1}$, Mohd Shukri Ab Yajid ${ }^{2}$ \& Ali Khatibi ${ }^{3}$
}

\author{
${ }^{1}$ Management and Science University, Shah Alam, Selangor, Malaysia \\ ${ }^{2}$ Management and Science University, Shah Alam, Selangor, Malaysia \\ ${ }^{3}$ Management and Science University, Shah Alam, Selangor, Malaysia
}

Correspondence: Erabaddage Gishan Tharanga Sumanasiri, School of Graduate Studies, Management and Science University, MSU Colombo Learning Center, No 300, Galle Road, Colombo 03, Sri Lanka. Tel: 94-773-660-929 Email: gishan@gmail.com

Received: May 8, 2015 Accepted: July 16, 2015 Published: August 1, 2015

doi:10.5296/jse.v5i3.7983 URL: http://dx.doi.org/10.5296/jse.v5i3.7983

\begin{abstract}
There is increasing pressure from governments, funding organizations, students and parents on universities around the world since graduate employability has been clearly recognized as one of the main objectives of university education. Accreditation bodies also appear to measure quality of education through the contributions made towards employability. In such a context one would assume that employability of university graduates to be clearly understood and extensively researched area. However, the real situation appears to be one which requires the urgent attention of all stakeholders of university education. A review of literature on graduate employability is a clear need today and current paper achieves this by summarizing the major articles on university graduate employability theoretical frameworks and empirical studies. Despite the large number of studies, graduate employability appears to be suffering from the problems of lack of theoretical control and politicization which appear to have become major obstacles for future developments of the concept.
\end{abstract}

Keywords: Employability, graduate, university, skills, politicization, university, higher education, learning 


\section{Introduction}

The concept of employability affects both individuals and society at large. Employability has been subjected to many studies and is at the center of discussion in this study. There are many recent studies on this area (Sumanasiri et al, 2015 Smith et al, 2015; Finch et al, 2013; Wickramasighe \& Perera, 2010; Chandrasiri, 2008; Pool \& Sewell, 2007; Knight \& Yorke, 2004; de la Harpe, et al., 2000; Hillage \& Pollard, 1998) and it is clearly evident that the concept is nothing new and has been subjected to numerous studies during last five decades. Many governments, universities, employers and other stakeholders have given various suggestions on increasing graduate employability. Despite these extensive developments and evidence of innovative practices to increase employability within universities, employability still remains to be a complex and problematic area without much clarity or complete direction (Rae, 2007). In one of the earliest studies "Robbins report on employability" commissioned by UK government, employability was identified as one of the four main objectives of higher education (Robbins, 1963). There is a clear relationship between employability of university graduates and the actual learning activities that they engage in university degree programs (Sumanasiri et al, 2015). Even though the employability has been subjected to various studies during the last five decades majority of them were based on case study approach and findings could not be generalized to other contexts mainly because they lacked quantitative evidence and gave only prescriptive advice (Wickramasinghe \& Perera, 2010). Even the few quantitative and empirical studies on employability have not given conclusive evidence. To add to this complexity, it has been shown that different stakeholders like faculty, employers and students understand the employability concept differently (Wickramasinghe \& Perera, 2010). In such a context current paper on graduate employability is both timely and important.

\section{Review of theoretical frameworks on employability of university graduates}

The review of literature clearly highlighted the presence of several main theoretical frameworks that attempts to identify the concept of employability of university graduates and its underlying factors. Among the many frameworks, the study done by Hillage \& Pollard (1998) can be considered pioneering since for the first time it summarized all previous and existing ideas about employability. Accordingly employability has four main elements namely; assets, deployment, presentation, and contexts. Even though Hillage and Pollard (1998) employability model was instrumental in summarizing the ideas about employability, it did not explain the underlying factors of employability or their associations. Many subsequent studies were conducted based on "employability skills" which are underlying skills factors that lead to graduate employability and, the theoretical framework presented by Cotton (1993) identifies a collection of basic, higher order and effective employability skills required by employers. The "employability skills model" has been the focus for many subsequent studies due to its simplicity and practicality. According to Cotton's model employability skills were categorized into three types; basic skills, higher order thinking skills, affective skills and traits. Skills model is considered by many as one of the earliest models of employability, which is based on the notion that employability depends on the skill levels of the individual, without any mention of other factors such as attitude, behavior, and 
experience which limits its broad usage. Overreliance on skills has been criticized as a main weakness of employability skills model and has been the focus of many recent skills plus employability frameworks that clearly argues employability skills are not adequate for meaningful employment (Knight \& Yorke, 2004; Knight \& Yorke, 2002). A skills plus model of employability has been presented as an alternative concept of employability based on findings from capability concept, social and psychology, and ideas from literature (Knight \& Yorke, 2002). USEM models is based on acronym for Understanding, Skills (subject-specific and generic), Efficacy beliefs (and self-theories generally), and Metacognition (including reflection). USEM model is widely considered as a major development in employability research since for the first time employability was conceptualized in relation to other constructs such as skills, subject understanding, meta-cognition and personal qualities. However the model is largely theoretical and lacks research evidence (Pool and Sewell, 2007) and the complexity does not allow practical use of this model to explain the concept to students and parents (Pool \& Sewell, 2007). Despite these limitations, many studies were based on USEM framework highlighting the significance of this theoretical framework.

CareerEDGE model is an alternative model that combines all the main factors of USEM, and employability skills models while bringing much needed clarity and simplicity. According to Pool \& Sewell (2007) CareerEDGE model presents a practical and simple overview of the relevant factors included in the employability process. The model explains the manner in which five lower order factors, namely; career development learning, experience, degree subject knowledge understanding and skills, generic skills, and emotional intelligence that allow students to reflect and evaluate these experiences. Employability is achieved through a complex interaction with social concepts such as self-esteem, self-efficacy, and self-confidence. CareerEDGE model signifies an attempt to operationalize the concept of employability since for the very first time in employability research this model appears ready for quantitative testing (Pool \& Sewell, 2007) which will allow generalization of findings unlike most previous studies which were either qualitative or case-study based which limits the application of findings. However CareerEDGE model suffers from the limitation of being categorized as a snap-shot view of employability (Smith, et al., 2014) that limits its applications. Despite these limitations CareerEDGE model is a comprehensive and widely accepted model of employability (Smith, et al., 2014; Pool \& Sewell, 2007)

A practical and a straight forward approach towards employability development process was discussed by Harvey (2010) who stated that higher education institutes provides a range of employability improvement opportunities for students including self-presentation, life-long learning and many others. Certain developments are implicit and embedded in degree programs while others are explicitly visible and developed as add-on modules. "Employability development model" was presented and clearly represents the roles of graduates, higher education institutes, employers and employment in generating employment, while highlighting that employment of a graduate should be seen only as an indicator of graduate individual employability and institutional enhancements are not the reason for this. The integrated competence model of employability proposed by Wellman (2010) 
demonstrates the interaction between various elements of knowledge, skills and personal attributes to create an improved level of employability. The model combines occupational and personal attributes into an "integrated topology" that combines various micro, macro and meta competencies. This appears to be a novel view of employability that combines technical and vocational knowledge and general support micro-level competencies with macro-level behavior and attitude. The model also considers enabling factors such as policies, strategies, systems and resources that promote effective employability. However the complicated and theoretical nature of both "employability development model" and "integrated topology model" limits their application as a practical employability model.

Other notable employability models include JET (Journey of Employment) proposed by (Copps \& Plimmer, 2013) challenges the findings of Harvey (2010) and states that employment process is not linear and many of the factors contribute towards it. Also it is mentioned that since everyone's journey is different there is no guarantee that one single factor will ensure employability for all. The JET model agrees with the satisfying definition of employability presented by Harvey (2010) and states that the job outcome represents not just about getting and sustaining employability and also includes quality of work and satisfaction gained (Copps \& Plimmer, 2013). In a context where the number of constructs in employability is increasing (Smith, et al., 2014; Hogan, et al., 2013) a fresh view point is needed that provides a simpler and clearer view without much complexity. The idea of RAW framework of employability was to address these concerns by providing a clear view of employability. The RAW model of employability uses the acronym RAW where; R Rewarding, A - Ability, and W - Willingness. Since RAW framework has streamlined the previous employability research concepts without losing the inherent attributes that represent employability its contribution to literature is recognized (Study \& Kottke, 2014). This however does not solve the problem of lack of research support associated with many employability frameworks since many employability models are only theoretical in nature (Wickramasinghe \& Perera, 2010). Since there is no clear agreement about the most suitable employability framework (Smith, et al., 2014) current paper attempts to review the main studies to guide future research work.

\section{Review of empirical studies on employability}

The review of literature revealed that employability has been subjected to many empirical studies. The following section summarizes the main empirical studies on employability during the last decade while focusing on identifying the main factors that influence employability of university graduates.

Since most employability studies are based on skills approach there is a need for an alternative approach that recognizes the complexity of human behavior (Holmes, 2001). Identity approach for employability leads to the suggestion that undergraduate curriculums must be enhanced. The series of studies done by Knight \& Yorke (2002) was instrumental in shaping the concept of employability from its early ideas. According to "skills plus" project employability is a far more complicated than just key skills as proposed by many academics, and is clearly different from graduate employment (Knight \& Yorke, 2002). Employability 
can be embedded in any subject curriculum without compromising academic freedom or stakeholder expectations of current academic values. The USEM model presents employability as "a synergetic blend of subject understanding, personal qualities, and key skills". The key feature of the USEM model is the fact that its pedagogic approach does not force academics to compromise the subject specific understanding and hence it should enjoy large scale support from academic and research community. The skills plus framework explains the need for complex learning in undergraduate programs to promote employability (Knight \& Yorke, 2003). This does not challenge teachers attachments to subject content while teachers much design positive learning environment that help students to answer the questions of what? how? and why? they learn. Skills plus framework is presented as an ambitious employability project since it considers entire academic programs while supporting academic's focus towards 'good learning' (Knight \& Yorke, 2003). The skills plus framework gained momentum with the series of studies undertaken by ESECT (Enhancing Student Employability Coordination Team) which were intended for teaching staff in higher education institutes that are keen in developing the employability of their students (Yorke, 2006). Accordingly higher education institutes are increasingly pressurized to produce graduates with relevant employability and enterprising skills so they are confident to set up businesses. Overall the USEM framework and skills plus project can be considered as a major development in the area of graduate employability.

Studies have also focused on the preoccupation of academics with regard to developing generic skills and resulting increases in employability (Brown, et al., 2003). The study done by Brown et al.,(2003) questions the thinking behind development of key skills, cost effectiveness of such development initiatives while questioning the practicality of major curriculum changes in a context of limited funding, and suggests more attention to be given towards post-graduate induction programs than pre-graduation period. The transition from university to labor market requires an active involvement for students who consider that employability is a crucial issue that must be successfully managed (Tomlinson, 2008). Employability development process involves improvements in graduate profile, credentials, attitude, and labor market strategies while the management of tensions, pressures and disappointment also play a key role in this. Also it is stated that students no longer see a clear link between their university academic achievements and rewards in the labor market. Students see a need to develop more aggressive and proactive labor market strategies surpassing the achievements in formal education settings.

Studies have explored the connection between the enterprise education in universities and subsequent employability and career development and identified a clear link between individual learning and institutional integration of enterprise, personal and career development (Rae, 2007). Challenges faced in this integration include academic management, academic culture, and perceptions of employers, institutional experience and expectations and behavior of students. The study by Rae (2007) suggests the need to increase the interactions between university students, faculty, and employers using innovative learning methods which include both curricular and extra-curricular activities. The study suggests two levels of integration; first at institutional level between university and employer, second at government 
policy level which has been suggested earlier by Dearing report on UK higher education system (NCIHE, 1997). The employability study done by Pool \& Sewell (2007) can be considered as a significant achievement since it presented a clear, straightforward, and practical approach of employability which was identified as a major requirement. CareerEDGE model identified five independent constructs that constitute employability which includes; career development learning, experience, subject skills-knowledge-understanding, generic skills and emotional intelligence. The CareerEDGE framework or "key to employability model" as its popularly referred introduces employability as a life-long concern since no one achieves perfect employability. The model considers reflection and evaluation which allows students to assess the learning experience and to understand what to be done further. Also the model clearly identifies three Psychological constructs that influence employability of individuals including self-efficacy, self-confidence and self-esteem. Furthermore, Pool \& Sewell (2007) provides a working definition for employability as "set of skills, knowledge, understanding and individual attributes that makes an individual more likely to choose and secure occupations in which they are satisfied and successful".

Further studies have challenged the existing concepts on employability while introducing new definitions which consider the evolution of employability over time and critical variables that influence employability at both organizational and individual levels (Clarke, 2008). Suggestions were also offered on managing employability and careers at individual and organizational level. Since employability is clearly dependent on organizational context as well as on individual responsibility, current focus towards individual employees must change and organizations must consider new ways to support their employees to manage employability and careers (Clarke, 2008). Since employability does not guarantee employment but however increase the chances of obtaining suitable employment, compared to other job seekers, understanding how to manage employability is more important that just understanding what employability is. How individuals can enhance their employability compared to others in job market, and the role organizations can play in employability development was studied in detail. Clarke (2008) study can be considered parallel to previous connected studies on employability which clearly links individual learners and their environment rather than considering things on isolation. Clarkes' study clearly highlights that defining employability as "having skills and abilities to get employment, remain employed, and to find new employment when required" earlier by Hillage \& Pollard (1998) is problematic since skills and abilities alone does not guarantee employment while attitude and behavior, individual characteristics, and labor market conditions all play an integrated role in generating employability (Clarke, 2008). In reality most individuals are unable to change or influence their internal or external labor market while only those in high levels of career mobility have opportunity to influence their environment. Clarkes' study can be considered one of the most comprehensive in employability literature since it brings ideas from different perspectives of employability without limiting to single point of view unlike other previous work on employability.

Review of literature reveals that certain employability studies have been limited to respective 
countries and their graduate employability. For instance Sri Lankan university graduates employability was studied and cross comparisons were made revealing that Engineering/ Science / Management graduates have more job opportunities compared to Social science / Humanity graduates (Ariyawansa, 2008). A comparison of the education quality revealed that Social science / Humanity degrees are of higher quality than some of the medical and Engineering degrees. The study done by Ariyawansa (2008) contradicts with previous employability studies and states IT skills and English language is not the focus for universities. In a context where many graduates consider training / experience as an important aspect in private sector, an improvement in IT skills, leadership qualities, team-work, analytical ability, and interpersonal relationships is vital parallel to university degree related learning. The mismatch of demand and supply for graduates in employment sector has in fact resulted in the variation of employability among university graduates. Accordingly the study on employability of Sri Lankan university graduates appear to be parallel to similar employability studies done overseas such as connected model which considers both the graduate and their environment that interact with each other in creating employability.

The value of enterprise education was clearly identified and integrated into academic curriculums through suitable pedagogical changes (Ehiyazaryan \& Barraclough, 2009) in a manner that will match students' academic degree programs to their intended further employability experience. Clearly the real-world experience is an essential step in employability while students are motivated when the subject matter is presented in a manner that is similar to real-life business situations. Furthermore improvements in student behavior results in improved confidence and decision making. Also the design of learning environment impacts the way in which students work together in their learning activities which reflects work environments. The study focuses on effective employer engagement and independent learning while highlighting the need for further research on teaching pedagogy which is relatively under researched.

The way graduates perceive, invest time and effort in, managing and developing employability (Nilsson, 2010) which reveals that hard, technical and vocational skills have less impact compared to soft-skills and personality attributes. The findings of this study agrees with those of Clarke (2008) who suggests that employability does not depend only on individual characteristics, while the work environment, context and other relations are important in determining one's employability. However the responsibility of managing and developing one's employability is a collective responsibility of individual, organization and university (Rae, 2007; NCIHE, 1997). The study gives a new definition for employability stating that "it is the ability of individuals to find and remain employed" which is exactly required to face the complexities and insecurities of modern work life (Nilsson, 2010). Since university degree programs are expected to make the graduates ready for future professional work challenges, graduates are also expected to be ready to handle employers' demands and expectations in an environment where employability is considered a responsibility of each individual graduate (Nilsson, 2010).

The value of university degree in employability was further questioned by Wellman (2010) and study of employability of marketing graduate reveal that less than half of employers 
demanded a university degree and less than quarter required a degree in marketing while experience was identified as a general requirement. The study of 250 person specifications for entry-level marketing positions revealed the presence of three types of attributes; academic and experiential qualifications, transferable skills, and personal traits. According to findings the degree academic content appear to be less important compared with work experience requirements. Transferrable skills include communication, ICT, interpersonal relationships, self-management, planning, decision making, and problem solving. Personal competencies such as creativity, responsibility, determination, confidence and imitativeness were also identified as important in generating employability among graduates (Wellman, 2010). The Wellman's study can be considered significant since it clearly identified the interplay between various elements of knowledge, skills and personal attributes in developing an integrated competence model of employability.

The perceptions of employers, university lecturers, and graduates have towards employability are said to be different (Wickramasinghe \& Perera, 2010) and was the focus of a study that was performed using entry-level graduates working in IT sector in Sri Lanka. There are clear differences in priorities for employability skills by male graduates, female graduates, employers, and lecturers while employability skills are said to be influenced mainly by graduate gender. University graduates prefer to acquire these skills while university lecturers and employers wants their graduates to have these skills. All three groups identified problem solving, self-confidence, and team work as the most important factor towards employability. Despite these similarities there appear to be clear difference towards employability among university graduates and their employers (Wickramasinghe \& Perera, 2010). Clearly, the male and female graduates have different perceived levels of employability skills while their focus towards employability also appears to differ significantly. For instance female graduates demonstrate higher level of importance to all employability skills apart from oral communication compared to male graduates. Also it was noted that female graduates demonstrate higher level of "self-confidence" and "learning skills" compared to male graduates. Study identified the need to improve the quality of transferrable skills since both male and female graduates appear to perceive their actual skill levels as less than ideal level required for employment. Also the study revealed that apart from problem solving skills, level of skills possessed by graduates and level of skills expected by employers do not differ for other employability skills. Accordingly graduates can assess their skill levels by comparing with skill requirements for each job position prior to applying for that new post.

The pressure from government and other funding agencies appear to have forced employability to be measured with getting and retaining fulfilling work (Hillage \& Pollard, 1998). However the outcome based evaluation of employability is troublesome since the employability is treated as an institutional achievement rather than the ability of individual students to get employment (Harvey, 2010). The study by Harvey (2010) presents employability as "the propensity of students to obtain a job" while providing supportive evidence from existing employability literature. The operationalization of employability is analyzed and the popular "magic bullet" approach is rejected due to its lack of practical usage. In real-life situations, employability appear to be far more complicated due to the different 
interactions students have with their university which are both implicit and explicit in nature, and relationship between recruiters and graduates which can be either rational or irrational in nature. A complicated and alternative model of employability is outlined based on the institutional audit of employability-development is presented. Evaluation of employability must clearly indicate areas for internal improvement without simply ranking universities without consideration for individual achievements. Since employability is considered as an attribute of individual student rather than of the institution, Harvey (2010) proposed audit of employment development opportunities or "employability audits" to measure the extent to which graduates from a particular university have developed these appropriate attributes. It's vital to identify the institutional contribution towards employability since in many instances it's difficult to differentiate between what developed by university and what is developed by graduates on their own without the contribution of their university. Since employability league tables provide misleading and counterproductive information, any employability audit must be based on internal and longitudinal benchmarking that will compare and evaluate employability outcomes with inputs and processes (Harvey,2010).

Employability has been presented as an aspect of quality of higher education and as a benefit of university degree programs for career and work (Storen \& Aamodt, 2010). The study questions how well universities are preparing their graduates for the working life while demonstrating that study program characteristics have a significant impact on the value of the program in working world. Furthermore the study considers the variation of employability across 13 different countries, study fields, program characteristics, and labor market conditions. Relatively large differences were reported with regard to usefulness of study programs based on country differences. The differences with regard to usefulness of study program based on fields of study were reported to be very small. However vocationally oriented degree program like as engineering, health, and law demonstrate positive effect on the employability compared with degree programs such as humanities and social science which are not vocationally oriented programs. According to Storen \& Aamodt (2010) study on the quality characteristics appear to have minor effects on the chances of getting a job but appear to have a significant effect on doing the job. The approach to investigate individual graduates' perceptions about the usefulness of study programs to their employability makes the study on education quality similar in focus to studies that suggest that employability is a responsibility of each individual graduate (Nilsson, 2010; Clarke, 2008).

The attitudes of recent graduates, human resource managers, and faculty towards employability skills required for performance was measured (Rosenberg, et al., 2011) revealing major differences of attitudes among the three parties. A triangular design approach was adopted and study demonstrated the differences in attitude towards 47 types of employability skills measured, concluding the requirement for better communication between these three important stakeholder groups. Study identified the need for graduates, faculty and industry to work closely in order to successfully promote employability. Leadership skill was identified by all three parties to be a critical skill that influence job performance while the study confirmed the earlier findings where graduates demonstrate leadership skills below industry expectations. Respondents also demonstrated different attitudes towards certain 
employability skills. For instance interpersonal skills were rated high by graduates and faculty while basic numeracy and literacy were rated high by graduates and human resource managers. All three respondent groups appear to consider systems thinking to be low in significance. Furthermore all parties have identified the need for additional training, and work ethics among recent graduates. In today's highly competitive economy there is little chance for graduates who are less prepared to achieve the industry expectations.

The views of undergraduates, the final recipients of the employability is clearly under represented (Tymon, 2013) and can reveal vital information about the motivation and commitment of individual learners since effective outcomes depend on them. The study clearly highlighted the lack of agreement among the views of students and other stakeholders about the active engagement with employability skill development initiatives. Differences were observed even between university students in different academic years which might explain the lack of engagement with employability development programs. The study makes practical and relevant suggestions that can be implemented within universities to improve student engagement and resulting employability development. The views of Tymon (2013) are similar to earlier studies on employability as individual graduate's responsibility (Storen \& Aamodt, 2010; Nilsson, 2010; Clarke, 2008). The study also highlights the value of work experience in employability since work-based training is widely considered as the best way to develop many employability skills and personal attributes. Finally the study highlights the lack of attention shown by first and second year university students towards degree specialization and active engagement which reduces their employability since employers have the ultimate opportunity to be selective about the grades and type of graduate they hire which highlights to complicated nature of employability.

Employability studies clearly demonstrate that employers place highest value for soft-skills and lowest value on academic reputation (Finch, et al., 2013). 17 employability factors were identified from literature and they were grouped into five categories. The factors were ranked based on their significance towards employability. The study done by Finch et al., (2013) clearly demonstrated that improvements to new graduates employability must focus on learning outcomes which are linked to soft-skills development. Also graduates were recommended to highlight soft-skills and problem solving skills during recruiting. Employer perception approach used by Finch et al., (2013) clearly differs from student's perception approach (Harvey, 2010) and multiple stakeholder perceptions approach adopted by Rosenberg, et al. (2011). The employability factors identified by Finch et al. (2013) was positioned in descending order of priority and includes; listening skills, interpersonal skills, verbal communication skills, critical thinking skills, professionalism, written communication skills, creative thinking skills, adaptability, professional confidence, job specific competencies, leadership skills, work experience, job specific technical skills, academic performance, program reputation, knowledge of software, and institutional reputation. These employability factors identified by Finch et al (2013) appear to parallel to earlier findings of employability skills frameworks (Cotton, 1993). Therefore the development of soft-skills is considered essential in both academic programs and individual modules within the programs. The presence of increasing gap between content and skills developed in universities and 
industry expectations highlight the value of Finch's study on employability factors.

The lecturers perceptions towards the graduate employability has been subjected to in-depth studies (Morrison, 2013) highlighting that degrees offer transferable skills which provides future employability in business and finance. Students are encouraged to develop absolute employability which is considered more important. The study reveals that staff perceptions play an important role in the influence of social class, gender, and race on employability. It is stated that with increasing pressure on higher education systems lecturers are compelled to deliver employability focused curricula. More detailed research is needed to understand the perceptions of the staff members towards employability and their capacities in university education. Since females are considered a disadvanged group within the labor market earning lessor salaries than males while working females demonstrate low salary requirements. The employability study by Smith et al. (2014) highlights the problems in employability noting that the lack of clear conceptualization and theoretical control over employability since there is no agreement about a universal employability definition. The politicization of the construct due to various parties with different interests all trying to include their favorite sub-concepts has not helped the above conceptualization process. The generality of the employability concept require every skill, ability, capability, psycho-social attitude identified to be incorporated. Employability is presented as the "ability of graduates to start their work as effective professional employees from first day of employment" and employability appears to be an explicit outcome of national higher education systems of many of the countries. The concept of employability is immensely helpful to generalists and semi-professional degree holders to be clear about their future work. Clearly the employable graduates are distinguishable and show distinct attributes according to the empirical study of Smith et al. (2014). The employability dimensions highlighted in the study are; lifelong learning, professional practices and standards, integration of knowledge/ theory/ and practices. Informed decision making, graduation readiness, and collaboration.

\section{Conclusion}

In conclusion the review of literature on employability of university graduates reveals that the concept has different interpretations based on stakeholder perceptions on employability. Employability depends not only on the attributes of the individual graduates such as subject knowledge, experience, skills, and personality traits, but also on the faculty, curriculum, and pedagogy in university systems, and also on the employers who hire the graduates and their expectations. While there are large number of employability studies majority still appear to be focused on defining and conceptualization stages of employability, only limited number of studies have focused on operationalization of employability as a concept and the findings have confirmed the disagreement among various stakeholders about employability. For instance the popular CareerEDGE model (Pool \& Sewell, 2007) attempts to operationalize employability through five (05) lower-order constructs namely; career development learning, experience, subject knowledge, skills and understanding, generic skills and emotional intelligence which is mediated by reflection and evaluation along with three (03) higher-order psychological constructs namely; self-esteem, self-efficacy, and self-confidence. On the other hand Finch et al.,(2013) operationalizes employability through seventeen (17) factors which 
were grouped into five (05) higher order categories namely; soft skills, problem solving skills, functional skills, pre-graduation experience, and academic reputation which show clear differences to CareerEDGE framework lower-tier and higher tier constructs. Since there is no clear agreement about the definition and operationalization of employability, confirmatory factor analysis was used to measure the provenance and utility of six (06) factors namely; lifelong learning, professional practices and standards, informed decision making, commencement readiness, collaboration, and integration of theory and practice (Smith et al., 2014) which appear to bring new ideas about employability and its operationalization, which confirms our idea that there should be clear communication and consensus among stakeholders in employability, in order to successfully promoted as a worthwhile and useful outcome of higher education.

\section{References}

Ariyawansa, R. G. (2008). Employability of Graduates of Sri Lankan Universities. Sri Lankan Journal of Human Resource Management, 2(1), 91-103

Brown, P., Hesketh, A. \& Williams, S., (2003). Employability in a knowledge-driven economy. Journal of Education \& Work, 16(2), 108-126, http://dx.doi.org/10.1080/1363908032000070648

Chandrasiri, S. (2008). The Labour Market Experience of University Graduates in Sri Lanka. Higher Education Policy, 21, 405-423, http://dx.doi.org/10.1057/palgrave.hep.8300164

Copps, J. \& Plimmer, D. (2013). Inspiring impact - The journey to employment - a guide to understanding and measuring what matters for young people, s.1.: NPC.

Cotton, K. (1993). Developing Employability Skills, s.1.: Northwest Regional Educational Laboratory.

de la Harpe, B., Radloff, A. \& Wyber, J. (2000). Quality and generic (professional) skills. Quality in Higher Education, 6(3), 231-243, http://dx.doi.org/10.1080/13538320020005972

Ehiyazaryan, E. \& Barraclough, N. (2009). Enhancing employability: integrating real world experience in the curriculum. Education + Training, 51(4), 292-308.

Finch, D. F., Hamilton, L. K., Riley, B. \& Zehner, M. (2013). An exploratory study of factors affecting undergraduate employability. Education + Tranining, 55(7), 681-70.

Harvey, L. (2010). Defining and Measuring Employability. Quality in Higher Education, 7(2), 97-109, http://dx.doi.org/10.1080/13538320120059990

Hillage, J. \& Pollard, E. (1998). Employability: developing a framework for policy analysis, London: Department for Education and Employment.

Hogan, R., Chamorro-Premuzic, T. \& R.B., K. (2013). Employability and career success: Bridging the gap between theory and reality. Industrial and Organizational Psychology, 6, 3-16, http://dx.doi.org/10.1111/iops.12001 
Holmes, L. (2001). Reconsidering Graduate Employability: the 'graduate identity' approach. Quality in Higher Education, 7(2), 111-119, http://dx.doi.org/10.1080/13538320120060006

Knight, P. T. \& Yorke, M. (2002). Employability through the curriculum. Tertiary Education and Management, 8(4), 261-276, http://dx.doi.org/10.1080/13583883.2002.9967084

Knight, P. T. \& Yorke, M. (2003). Employability and Good Learning in Higher Education. Teaching in Higher Education, 8(1), 3-16, http://dx.doi.org/10.1080/1356251032000052294

Knight, P. \& Yorke, M. (2004). Learning, Curriculum and Employability in Higher Education, London: Routledge Falmer,

NCIHE. (1997). Higher Education in the Learning Society [Report of the National Committee of Inquiry into Higher Education: 'The Dearing Report'], s.1.: Norwich: HMSO.

Nilsson, S. (2010). Enhancing individual employability: the perspective of Engineering $\begin{array}{llll}\text { graduates. } \quad \text { Education } \quad \& \quad \text { 5raining, 52(6/7), } & \end{array}$ http://dx.doi.org/10.1108/00400911011068487

Pool, L. D. \& Sewell, P. (2007). The key to employability: developing a practical model of. Education + Training, 49, 277 - 289.

Rae, D. (2007). Connecting enterprise and graduate employability: challenges to the higher education culture and curriculum. Education + Training, 49(8/9), 605-619.

Robbins, L. (1963). Report of the Committee on Higher Education. [Online] Available at: http://filestore.nationalarchives.gov.uk/pdfs/small/cab-129-114-c-173.pdf [Accessed 29 January 2014].

Rosenberg, S., Heimler, R. \& Morote, E.-S. (2012). Basic employability skills: a triangular design approach. Education + Training, 54(1), 7-20.

Smith, C., Ferns, S. \& Russell, L. (2014). Conceptualising and measuring 'employability' lessons from a National OLT Project. Gold Coast, Australian Collaborative Education Network Limited, pp. 1-10.

Study, D. J. \& Kottke, J. L. (2014). Another Model of Employability? Considering the RAW Framework, California : Presented at the 26th Association for Psychological Sciences Annual Convention,San Francisco, CA,.

Sumanasiri, E. G. T., Yajid, M. S. A. \& Khatibi, A. (2015). Conceptualizing Learning and Employability "Learning and Employability Framework". Journal of Education and Learning, 4(2), 54-63, http://dx.doi.org/10.5539/jel.v4n2p53

Tomlinson, M. (2007). Graduate employability and student attitudes and orientations to the labour market. Journal of Education and Work, 20(4), 285-304, http://dx.doi.org/10.1080/13639080701650164 


\section{Macrothink}

Wellman, N. (2010). The employability attributes required of new marketing graduates. Marketing Intelligence and Planning, 28(7), 908-930, http://dx.doi.org/10.1108/02634501011086490

Wickramasinghe, V. \& Perera, L. (2010). Graduates', university lecturers' and employers' perceptions towards employability skills. Education + Training, 52(3), 226-244.

Yorke, M. (2006). Employability in Higher Education: What it is - What it is not, s.1.: Higher Education Academy.

Storen, L. A. \& Aamodt, P. O. (2010). The Quality of Higher Education and Employability of Graduates. Quality in Higher Education, 16(3), 297-313, http://dx.doi.org/10.1080/13538322.2010.506726

\section{Copyright Disclaimer}

Copyright for this article is retained by the author(s), with first publication rights granted to the journal.

This is an open-access article distributed under the terms and conditions of the Creative Commons Attribution license (http://creativecommons.org/licenses/by/3.0/). 